We happened to want to see what the author had to say about the partridge, and naturally turned to the letter P, where no such name occurs. At last we find the bird, together with several other species, under the entry "Common," which, to say the least, is absurd. In fact, the prefix of "common" to the partridge is not required at all.

R. L.

\section{ADMIRALTY REORGANISATION.}

$\mathrm{T}_{\mathrm{HE}}^{\mathrm{HE}}$ $E$ official memoranda published by the First Lord of the Admiralty on January 8 are of great interest, but that relating to the Naval War Staff is of much greater importance than the other two. Mr. Churchill discusses at considerable, if not unnecessary, length the distinctions which he believes to exist between "naval and military problems," apparently considering it necessary to justify differences of organisation which will be found at the Admiralty and at the War Office when the new scheme has been developed. The First Lord is an able and forcible writer, who might be expected to state his case well, but it may be questioned if it would not have served his purpose better and have given a clearer understanding of the subject to the public if his memorandum on the Naval War Staff had been less diffuse. The fact is admitted by him that "during the course of years all or nearly all the elements of a War Staff at the Admiralty have been successively evolved in the working of everyday affairs." The edifice is now to be completed and crowned by combining "these elements into an harmonious and effective organisation." It is proposed "to invest the new body with a significance and influence which it has not hitherto possessed, and to place it in its proper relation to existing powers." This is obviously both wise and necessary action; but it is scarcely to be described as such a radical change as some persons have asserted.

In the current Navy Estimates provision is made for a Naval Intelligence Department and a Naval Mobilisation Department, each under a naval director (rear-admiral or captain), the former department including twenty-one naval officers and thirteen civilians, the latter six naval officers and four civilians. The total cost of these departments is about $22,000 l$. per annum. Both departments are placed under the First Sea Lord, and their duties are sufficiently indicated by their names. In the new scheme they will continue in existence, and a third section is to be added, to be known as the "Operations Division," and to be placed under a director. All three sections are to be combined together under a chief of the staff, who is to be "a flag officer, primarily responsible to the First Sea Lord, and working under him as his principal assistant and agent." "Constant, free, and informal intercourse between the three sections] is indispensable"; and it is laid down that each of the directors is "to be kept fully acquainted with the work of their two colleagues."

All this is admirable, but the principles involved are in no sense novelties at the Admiralty; nor is it conceivable that the consideration of "war plans" which is stated to be the special business of the new section-has not been practised at the Admiralty hitherto. Long-continued peace has tended to drive somewhat into the background the primary importance of a scientific study of operations and preparation of "plans of campaign," but it is well known that the great shipbuilding programmes which have been carried out during the last twenty-five years have been based-as they ought to have been-on strategical plans prepared by the Admiralty for the naval defence of the British Empire, its commerce and communications. While this is true, it is equally true that the enormous increase of the Royal Navy, the growth of rival war fleets, and the present complex conditions of naval warfare, have all emphasised the need for greater attention and closer study of the subject by competent persons. Consequently there can only be universal and hearty welcome of the endeavour now made to meet the pressing necessity by the development of an advisory War Staff at the Admiralty.

\section{NOTES.}

M. Lippmann has been elected president of the Paris Academy of Sciences for the present year, and Prof. Guyon vice-president.

THE Academy of Sciences of the Royal Institute of Bologna has awarded the Elie de Cyon prize of 3000 lire for I9 II to Prof. E. A. Schäfer, F.R.S., of Edinburgh, for his work on the ductless glands, and especially for his recent work on the pituitary body

IT is proposed to establish in Dartmouth a permanent memorial to Thomas Newcomen, known for his work in connection with the steam engine, who was born in that town in 1663. A meeting of persons interested in the matter was held yesterday in the Dartmouth Guildhall. The Mayor of Dartmouth, Mr. Charles Peek, and Mr. T. F. Caston, the honorary secretary to the Newcomen Memorial Committee, will welcome suggestions as to the best manner of perpetuating the memory of the inventor and his invention, and be glad to receive contributions.

THe council of the Royal Sanitary Institute offers the Henry Saxon Snell prize for competition this year. The prize was founded to encourage improvements in the construction or adaptation of sanitary appliances, and is to be awarded by the council at intervals of three years, the funds being provided by the legacy left by the late Henry Saxon Snell. The prize will consist of fifty guineas and the silver medal of the institute, and is offered for an essay on "Suggestions for Improvements in the Ventilating, Lighting, Heating, and Water Supply Appliances and Fittings for an Operating Room and its Accessory Rooms for a General Hospital of 400 Beds (no Students)."

$A_{N}$ influential body of gentlemen interested in the preservation of our local antiquities has presented a memorial to the committee now engaged in considering schemes for the future utilisation of the Crystal Palace and its grounds, suggesting the establishment of a National Folk Museum. The nearest parallel to the proposed institution is the Northern Museum at Stockholm, with its offshoot the Open Air Museum at Skansen. The scheme suggests the erection in the Palace grounds of a series of typical ancient houses, each provided with appropriate gardens and furniture, and an open-air amphitheatre for pageants, folksongs, and dances. Part of the main building of the Palace might, the memorialists suggest, be devoted to exhibits of domestic art products, toys and games, a folklore room, a museum relating to the Royal House, and other exhibits illustrating the origin and evolution of the various departments of national culture. Something of the kind has been attempted in the Pitt Rivers Museum at Oxford, and the educational value of the culture series arranged by $\mathrm{Mr}$. H. Balfour supplies good evidence in support of the present proposals. The domestic appliances of past times are now disappearing so rapidly that unless active steps are taken at once it will soon be impossible to supply the exhibits needed for a folk museum such as that now suggested. 